\title{
Field Validation for the Constructability of Exposed Aggregate Concrete Overlay
}

\author{
Jaehoon Kim $\mathbb{D}^{1},{ }^{1}$ Makara Rith $\mathbb{D}^{1},{ }^{1}$ Seung Woo Lee $\mathbb{D}^{1},{ }^{1}$ and Young Kyu Kim $\mathbb{D}^{2}$ \\ ${ }^{1}$ Department of Civil Engineering, Gangneung-Wonju National University, Gangneung, Republic of Korea \\ ${ }^{2}$ Institute for Disaster Prevention, Gangneung-Wonju National University, Gangneung, Republic of Korea \\ Correspondence should be addressed to Young Kyu Kim; kingdom1980@nate.com
}

Received 26 July 2021; Revised 6 October 2021; Accepted 19 October 2021; Published 27 October 2021

Academic Editor: Eleftherios K. Anastasiou

Copyright (C) 2021 Jaehoon Kim et al. This is an open access article distributed under the Creative Commons Attribution License, which permits unrestricted use, distribution, and reproduction in any medium, provided the original work is properly cited.

Functional performance of existing concrete pavement is necessarily improved to maintain the low tire-pavement noise and the long-term skid resistance. Thus, exposed aggregate concrete overlay is introduced since these high functional performances are expected. Its surface texture requires the removal of cement mortar to expose the aggregates. This technique results a durable surface texture and an effective surface drainage through the random shape of aggregates. In Korea, concrete overlay is allowed to construct between 200 and 400 meters per day. This concrete amount is insufficient to use batch plant. Therefore, mobile mixer is employed to supply a consistent quality and on-time production. In addition, surface texture of this overlay method is significantly related to the reduction of tire-pavement noise. Accordingly, outcome of surface texture should be validated in the real field construction. This study intended to verify the constructability of exposed aggregate concrete overlay using mobile mixer for concrete production and deck finisher for concrete placement to acquire the surface texture and structural strengths. Surface texture and concrete strengths from mock-up and laboratory tests were measured and compared with design criteria. This research indicated that the suggested equipment and construction procedure can efficiently maintain the required surface texture of EACO for low tire-pavement noise and the adequate strengths for early traffic opening.

\section{Introduction}

Concrete overlay is an effective rehabilitation technique that extends the remaining structural capacity and improves the functionality [1]. Surface treatment-such as transverse tining-has been applied to improve the skid resistance. However, the drivers and nearby residents have complained about the increase in tire-pavement noise [2]. Further, skid resistance is typically reduced due to pavement aging, traffic repetition, and environment change [3]. Therefore, exposed aggregate concrete overlay (EACO) is introduced since it can maintain the long-term skid resistance and low tire-pavement noise [4]. Surface texture of this overlay requires the exposure of aggregates with sequential process. Initially, retardant agent is sprayed on the fresh concrete surface to delay the hardening of cement mortar. The 2- or 3-mm unset mortar is afterward removed by steel brush or water jet within 24 hours [5]. Additionally, this surface texture is durable due to random shape of aggregates thus resulting the long-term functional performance. Surface drainage is also improved by the grooves between aggregates [3]. Also, various research studies compared the performance of exposed aggregate concrete pavement (EACP) with other surface treatments. They confirmed that low tire-pavement noise, adequate resistance, and high structural performance can be achieved in EACO [6-8]. Most studies showed that exposed aggregate concrete pavement effectively produces lower noises than conventional concrete pavement about 3 to 7\% [9]. Additionally, compared with asphalt pavement, noise level can be decreased up to 2 to $3 \%$ in exposed aggregate concrete pavement [10]. Surface texture of exposed aggregate concrete overlay has significantly affected the noise level and skid resistance. This fact leads many research studies to focus on the texture parameters, material selection, and construction process. Fundamental properties of the exposed aggregate concrete pavements were investigated 
in the laboratory test [11]. The study evaluated the aggregate abrasion, retarder amount, construction method, and skid resistance. Consequently, a guideline of mixture design was suggested for the 13-mm exposed aggregate concrete pavement. Moreover, an optimum mixture design of finesize exposed aggregate concrete overlay was suggested by the optimum surface texture and structural strength [12]. Surface texture was characterized by mean texture depth (MTD) and exposed aggregate number (EAN). Various trial mixtures were performed with variation of coarse aggregates, high early strength cement, and aggregate amount. Lastly, the optimum mixture proportion was recommended.

Exposed aggregate concrete pavement is typically manufactured in the batch plant and placed by slip forms. However, for pavement rehabilitation purpose, concrete overlay length can only be constructed within 200 to 400 meters per day to avoid the traffic delay thus requiring a small amount of concrete that unnecessarily needs batch plant. Additionally, mobile mixer and deck finisher have typically been employed in concrete overlay project in South Korea. Mobile mixer is an on-site mixing technique that provides on-time material production for overlay construction. Afterward, deck finisher ensures a proper overlaying through rolling compaction. Surface texture of exposed aggregate concrete overlay is highly related to the tire-pavement noise. Thus, an optimum surface texture should be achieved in the field construction. Required surface texture is simply obtained in the laboratory. However, this may not be true for on-site construction due to the environmental condition and construction process. This requires a field verification to show the outcome of exposed aggregate concrete overlay. This study aimed to verify the constructability of exposed aggregate concrete overlay using mobile mixer and deck finisher to ensure the required surface texture for low tire-pavement noise and structural strength for early traffic opening.

\section{Research Methodology}

Constructability of exposed aggregate concrete overlay was validated by comparing the outcome of field tests with laboratory results and design criteria. Surface texture and structural strengths are the design requirement for the validation. Surface texture defines the functional performance while structural strengths express the ability to withstand the early traffic opening of concrete overlay. Mean texture depth (MTD) and exposed aggregate number (EAN) characterize the surface texture of exposed aggregate concrete overlay. Kim et al. suggested the optimum EAN and MTD for low tire-pavement noise in exposed aggregate concrete overlay [12]. Thus, these criteria are adopted in the present study to verify the surface texture. In addition, early structural strengths are evaluated for the requirement of early traffic opening. The mock-up test was performed by replicating the construction procedure of concrete overlay in the real rehabilitation project. Additional equipment and process of aggregate exposure were also included.
Furthermore, laboratory tests were conducted to reflect the achievement of experimental level to the field results.

\section{Mixture Design and Design Criteria}

3.1. Mixture Proportion of Concrete Overlay. Material composition of exposed aggregate concrete overlay (EACO) is comprised of high early strength cement, sand, coarse aggregate, and water as shown in Table 1 . High early strength cement was used to achieve the bearing capacity for the early opening of traffic. Large amount of cement was suggested to avoid the aggregate detachment from cement mortar during the process of aggregate exposure. Further, the 10-mm coarse aggregates were applied to maintain the low tire-pavement noise. Aggregate gradations for laboratory and mock-up test program are slightly different as shown in Figure 1. However, they satisfied the suggested upper and lower limits for concrete overlay [13]. Sand and coarse aggregate ratios $(s / a)$ for both test programs were 30 and $27 \%$, respectively.

\subsection{Structural Criteria for Exposed Aggregate Concrete} Overlay. Structural performance of existing concrete pavement can be extended by concrete overlay to withstand the future load. Furthermore, traffic close may disturb the traffic flow, and this is a concern in Korea. Therefore, KEC recommended the compressive and flexural strengths of $21 \mathrm{MPa}$ and $3.15 \mathrm{MPa}$, respectively, for the requirement of early traffic opening [13]. In addition, quality of fresh concrete was evaluated by slump and air void. Slump was suggested within $15 \pm 2 \mathrm{~cm}$ to maintain the workability of concrete overlay while required air void is between 5 and $7 \%$.

\subsection{Surface Texture Criteria for Exposed Aggregate Concrete} Overlay. Exposed aggregate concrete overlay has been introduced in rehabilitation project to reduce the tire-pavement noise. Surface texture of this overlay method is significantly related the noise reduction. Thus, the optimum surface texture was suggested for low tire-pavement noise in exposed aggregate concrete overlay [12]. This surface condition is comprised of mean texture depth (MTD) and exposed aggregate number (EAN). Recommended MTD is within the $1.2 \pm 0.5 \mathrm{~mm}$ while minimum EAN of $40 \mathrm{ag}$ gregate per $25 \mathrm{~cm}^{2}$ should be obtained. These criteria are adopted in the present study to evaluate the surface texture from field construction.

\section{Mock-Up Test Setup}

4.1. Field Testing Facility. The mock-up test of exposed aggregate concrete overlay was constructed in GangneungWonju National University (GWNU) of South Korea as illustrated in Figure 2. The construction started and finished on $4^{\text {th }}$ October 2019. Concrete slab was 30 meters in total length and 4 meters in width. $10-\mathrm{cm}$ slab was placed on the milled asphalt concrete pavement. Saw-cutting of joint was applied with the equal spacing of $6 \mathrm{~m}$. 
TABLE 1: Mixture proportions of exposed aggregate concrete overlay in mock-up and laboratory test.

\begin{tabular}{lccccccc}
\hline Test type & Max. size of coarse aggregate $(\mathrm{mm})$ & $W / C(\%)$ & $S / a(\%)$ & $W\left(\mathrm{~kg} / \mathrm{m}^{3}\right)$ & $C\left(\mathrm{~kg} / \mathrm{m}^{3}\right)$ & $S\left(\mathrm{~kg} / \mathrm{m}^{3}\right)$ & $G\left(\mathrm{~kg} / \mathrm{m}^{3}\right)$ \\
\hline Mock-up test & 10 & 45 & 27 & 189 & 440 & 430 \\
Laboratory test & 10 & 45 & 30 & 189 & 420 & 495 & 1185 \\
\hline
\end{tabular}

Note. $W$ : water amount; $C$ : cement amount; $S$ : sand amount; $G$ : gravel amount; $a$ : sum of sand and gravel amounts.

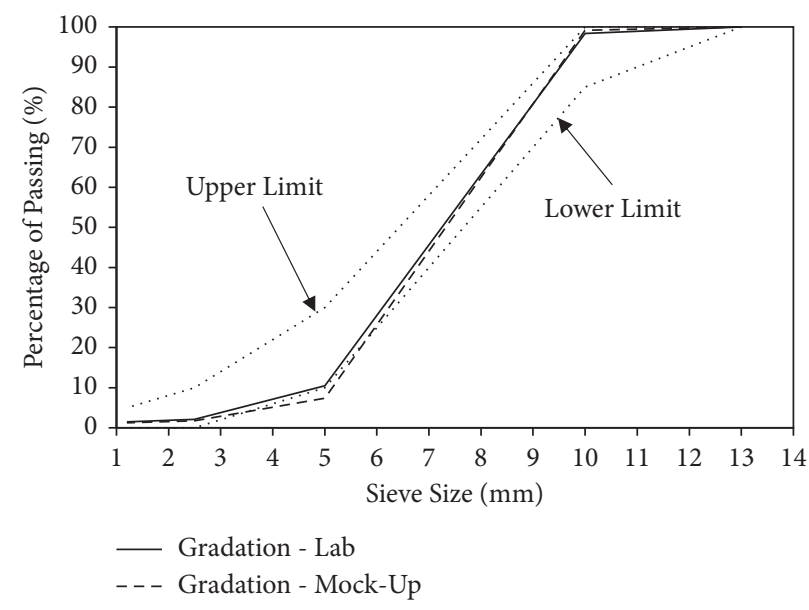

FIGURE 1: Aggregate gradations for laboratory and mock-up test.

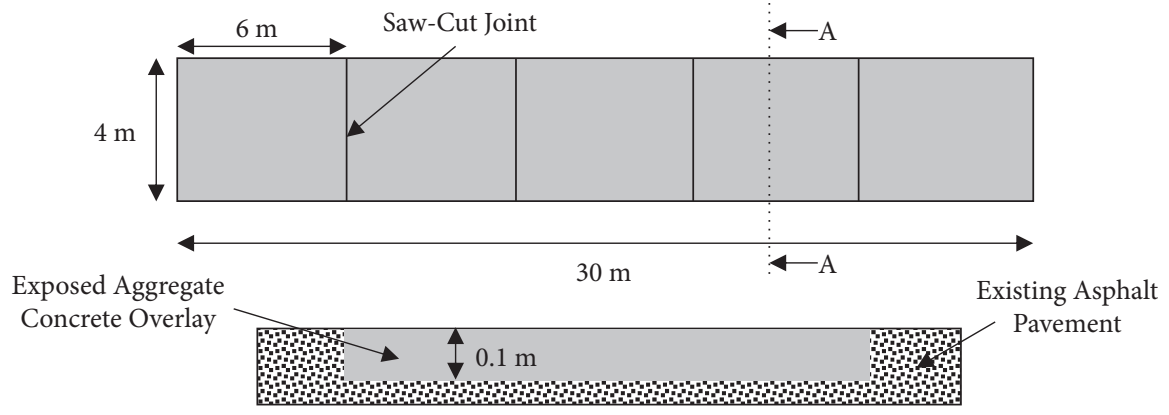

A-A View Section

(a)

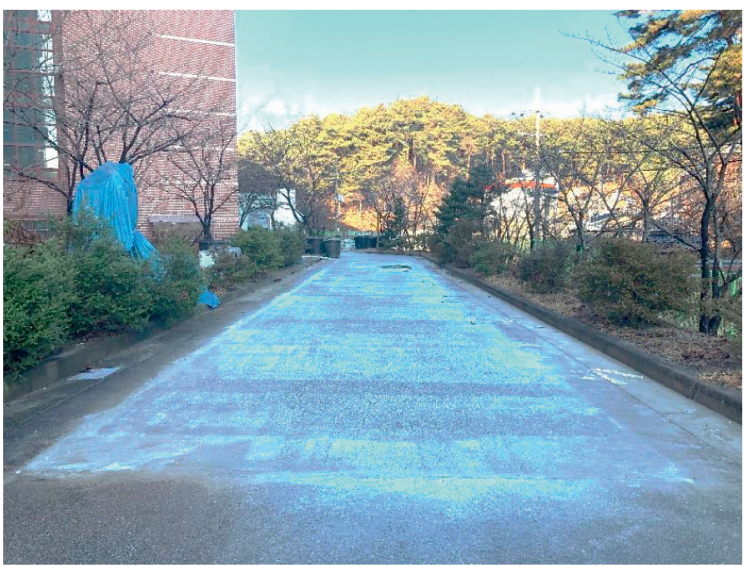

(b)

FIGURE 2: Mock-up test section: (a) plan view of exposed aggregate concrete overlay construction; (b) completion of exposed aggregate concrete overlay construction. 


\subsection{Field Testing Program}

4.2.1. Construction Process. Constructability of exposed aggregate concrete overlay was verified through mock-up testing program. Equipment and construction process replicated the actual rehabilitation project in Korea. Additional device and process of aggregate exposure were included in this study. Construction of the mock-up test is summarized in Figure 3. Initially, existing asphalt pavement was milled to achieve a uniform surface level. Exposed aggregate concrete overlay was then mixed and supplied by mobile mixer that was capable of supplying the concrete volume up to $7 \mathrm{~m}^{3}$. Workability of fresh concrete was controlled by slump and air void. Concrete mixtures were then carefully placed and compacted by deck finisher on the prepared substrate. Subsequently, the retardant agent was sprayed on the fresh concrete surface to delay the mortar hardening. Aggregates were exposed within 24 to 26 hours by the mobile steel brush. Further, concrete slab was cured by the white-pigment curing compound after completing the aggregate exposure. After 24 hours, the transverse joints were saw cut at the interval of 6 meters.

Mobile mixer conducts the continuity of material blending with the exact mixture amount every time as shown in Figure 4. Additionally, within seventy seconds of mixing, mobile mixer can produce similar workability to the laboratory test. Each mixing can be stopped and started again thus allowing the balance between production and construction crews. With this on-site mixing process, material quality can be consistently obtained since fresh concrete can be supplied without being late to the job site.

4.2.2. Measurement of Surface Texture and Strengths in the Field. Surface texture of exposed aggregate concrete overlay was characterized by mean texture depth (MTD) and exposed aggregate number (EAN). They were measured to evaluate the outcome of surface texture produced by real field construction. These two parameters were recorded from the two wheel paths and the center of each slab. As shown in Figure 5(a), MTD was measured by the sand patch test that follows the ASTM-E965 "Standard Test Method for Measuring Pavement Macrotexture Depth Using a Volumetric Technique" [14]. EAN can be estimated by counting the peak aggregates in a specified area of $5 \times 5 \mathrm{~cm}$ as indicated in Figure 5(b). Additionally, structural capacity of concrete overlay was evaluated by the compressive and flexural strength. Strength measurement adopted the same procedure of the laboratory test, and it was detailed in the next section.

\section{Laboratory Test Setup}

\subsection{Specimen Preparation}

5.1.1. Specimens for Surface Texture. Functional performance of exposed aggregate concrete overlay is significantly related to the surface texture. Optimum surface texture must be obtained to secure the low tire-pavement noise. This optimum condition can be evaluated by mean texture depth
(MTD) and exposed aggregate number (EAN). These parameters were measured from the concrete specimens that were prepared in the laboratory. Prismatic specimen of $30 \times 30 \times 10 \mathrm{~cm}$ was selected. Texture of exposed aggregate concrete was achieved through sequential process. Initially, fresh concrete was placed and vibrated in the wooden mold. Afterward, the coagulation retardant was applied on the surface to delay the hardening of cement mortar. All specimens were then cured for 24 to 26 hours. Lastly, the unset cement mortar is removed by steel brush to expose the aggregates as shown in Figure 6. The steel brush device was equipped with the $50 \mathrm{~mm}$ length brushing blades and run at 71.2 rounds per minute (rpm).

5.1.2. Specimens for Compressive and Flexural Strength Tests. Early structural performance of exposed aggregate concrete overlay was evaluated to confirm the structural capacity against early traffic opening. This performance was estimated by compressive and flexural strengths of concrete overlay. Field and laboratory testing programs adopted the same procedure of specimen fabrication. Cylindrical specimens of $\varnothing 10 \times 20 \mathrm{~cm}$ were constructed for compressive strength measurement following the KS-F-2405 "Method of test for compressive strength of concrete." Prismatic samples of $40 \times 10 \times 10 \mathrm{~cm}$ were selected from the flexural strength test. This process was based on KS-F-2325 "Testing method for flexural strength of soil-cement using simple beam with third point loading." Afterward, all specimens were properly cured in the temperature chamber.

\subsection{Testing Measurement of Surface Texture and Strengths in Laboratory}

5.2.1. Measurement of Surface Texture. Optimum surface texture of exposed aggregate concrete overlay was characterized by mean texture depth (MTD) and exposed aggregate number (EAN). MTD and EAN were measured after completing the aggregate exposure. Exposed aggregate number (EAN) is the amount of peak aggregates that were visible to the surface after removing the unset mortar. EAN is manually counted in the specified area of $5 \times 5 \mathrm{~cm}$ on the specimen surface as shown in Figure 7 (a). In addition, mean texture depth (MTD) is the average depth of macrotexture in the pavement surface. This parameter can be computed from the volumetric technique of ASTM-E965 "Standard Test Method for Measuring Pavement Macrotexture Depth Using a Volumetric Technique." This method applied the sand patch on the specimen surface. Afterward, MTD is determined through the known volume and the measured diameters of sand covering the surface as shown in Figure 7(b).

5.2.2. Measurement of Structural Strengths. Structural performance of concrete overlay is evaluated by compressive and flexural strengths as shown in Figure 8. Concrete specimens were fabricated and stored in the curing chamber. The 3- and 7-day strengths were measured to confirm the structural capacity against early opening of traffic. 


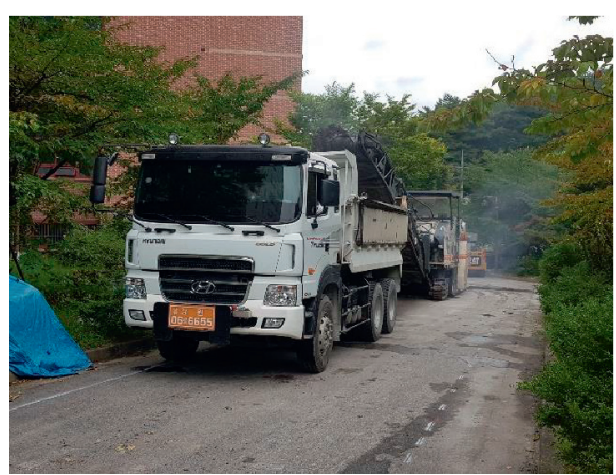

(a)

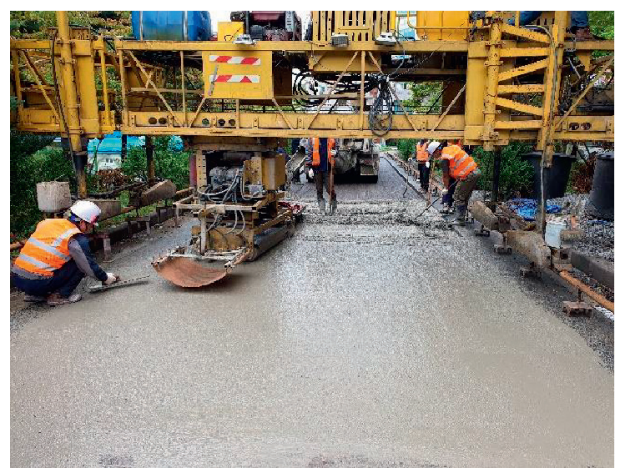

(c)

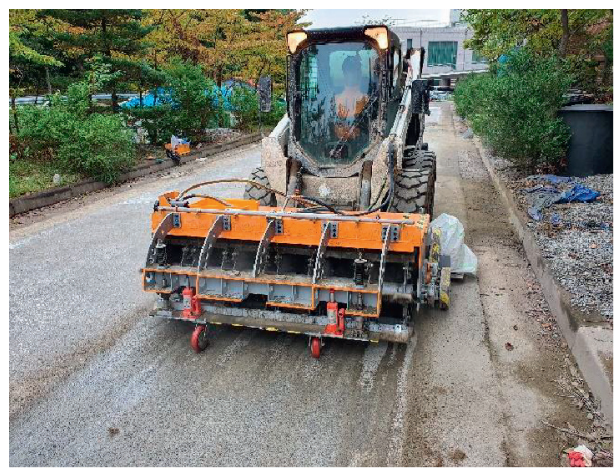

(e)

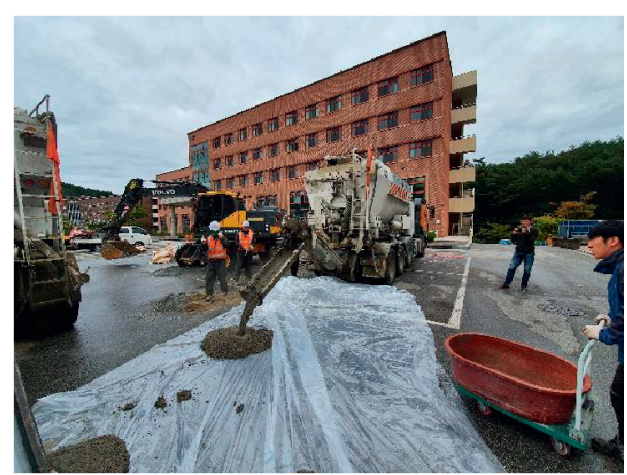

(b)

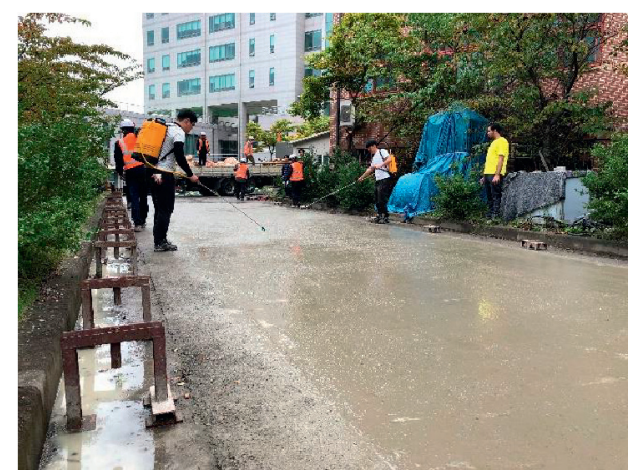

(d)

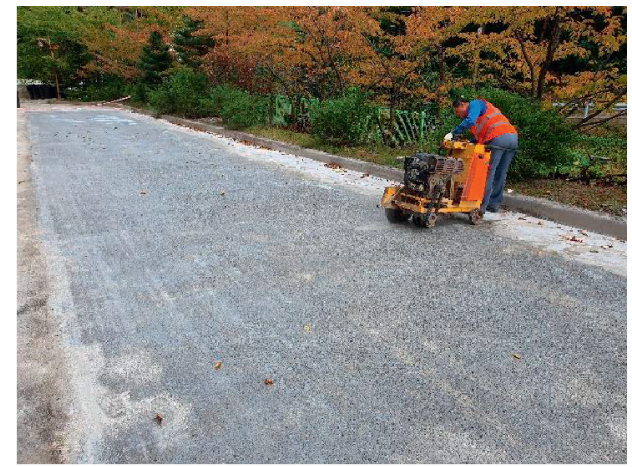

(f)

FIGURE 3: Mock-up construction process of exposed aggregate concrete overlay: (a) substrate preparation; (b) mobile mixer; (c) deck finisher; (d) spraying retardant; (e) exposing aggregate; (f) joint saw-cutting.

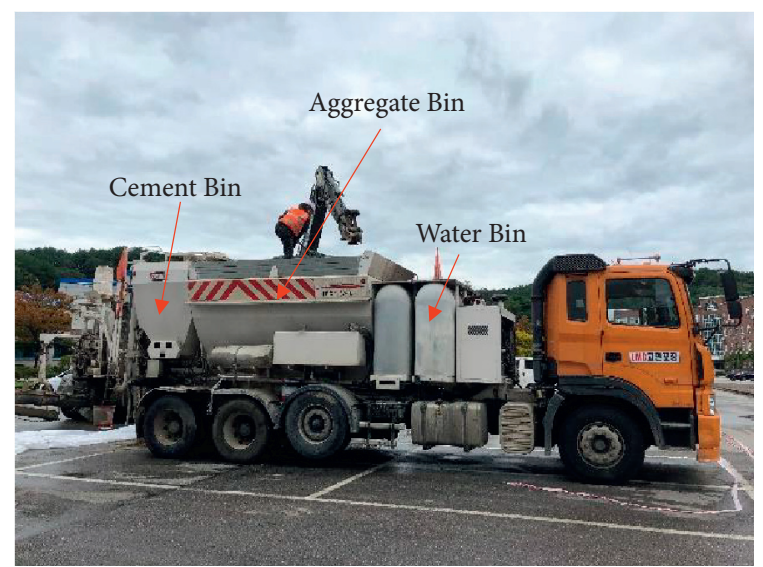

FIGURE 4: Mobile mixer for concrete overlay project.
Additionally, the testing procedure followed the KS-F-2405 "Method of test for compressive strength of concrete" and KSF-2325 "Testing method for flexural strength of soil-cement using simple beam with third point loading." Average strength was computed from three specimens.

\section{Results and Discussion}

6.1. Exposed Aggregate Number (EAN). Exposed aggregate number (EAN) is one of the surface texture parameters that characterize the reduction of tire-pavement noise. $\mathrm{EAN}_{\text {Mock-up }}$ is the value that was measured from the real field construction. EAN $\mathrm{Laboratory}_{\text {was }}$ recorded from the surface texture of concrete specimens, and it defined the reflection of experiment level on field performance. EAN derived from laboratory and 


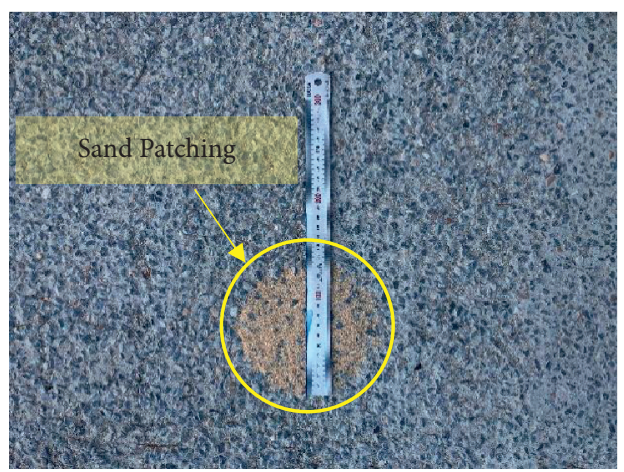

(a)

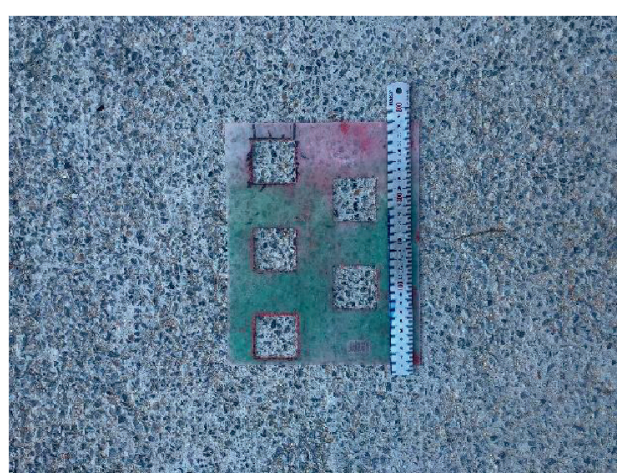

(b)

FIGURE 5: Measurement of surface texture parameters in the field: (a) mean texture depth measurement in the field; (b) exposed aggregate number measurement in the field.

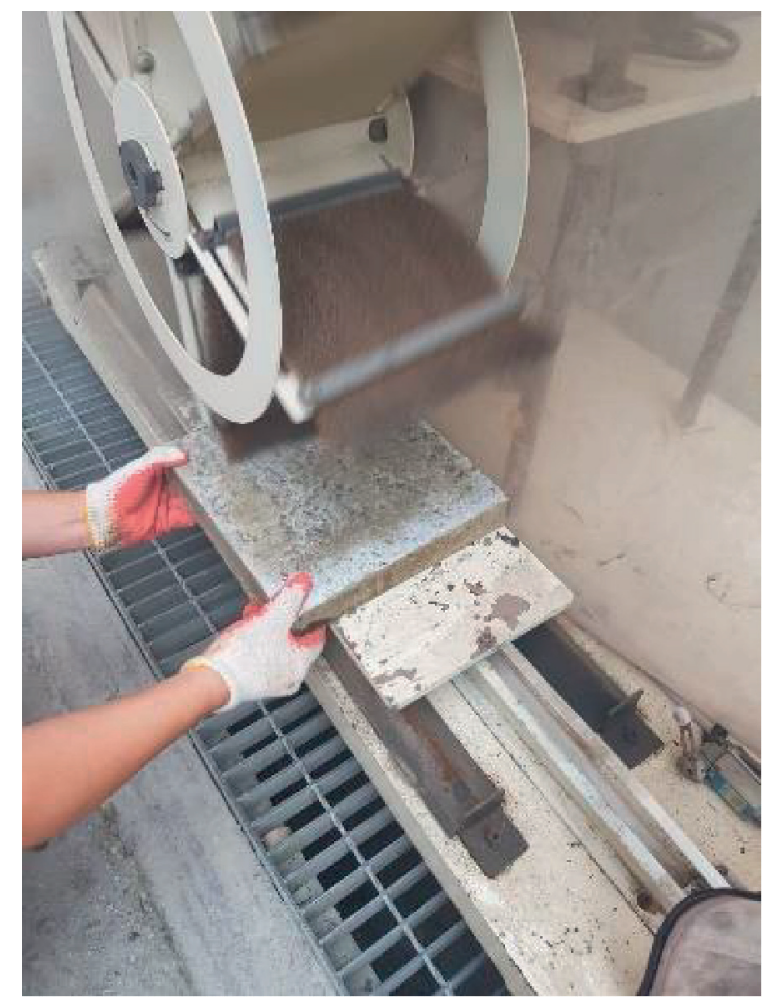

FIGURE 6: Aggregate exposure by steel brush in the laboratory.

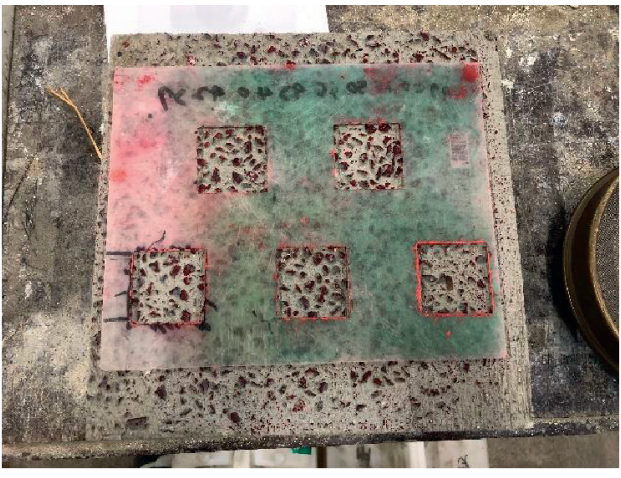

(a)

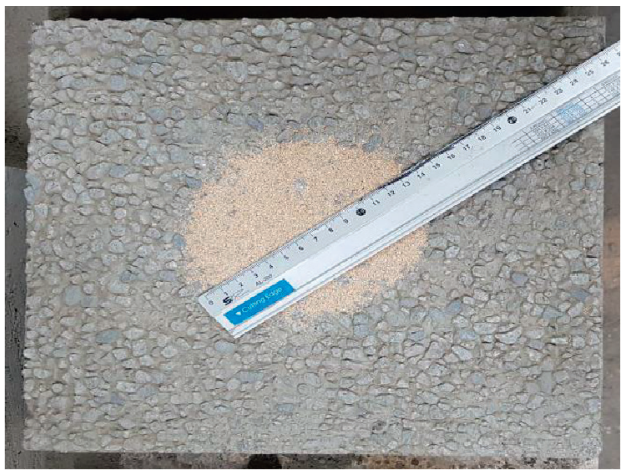

(b)

Figure 7: Measurement of (a) exposed aggregate number and (b) mean texture depth. 


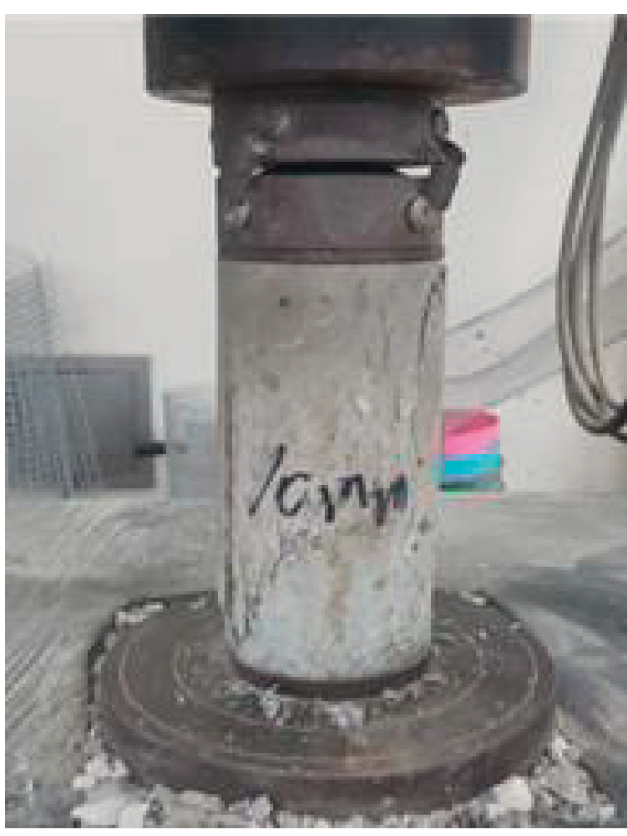

(a)

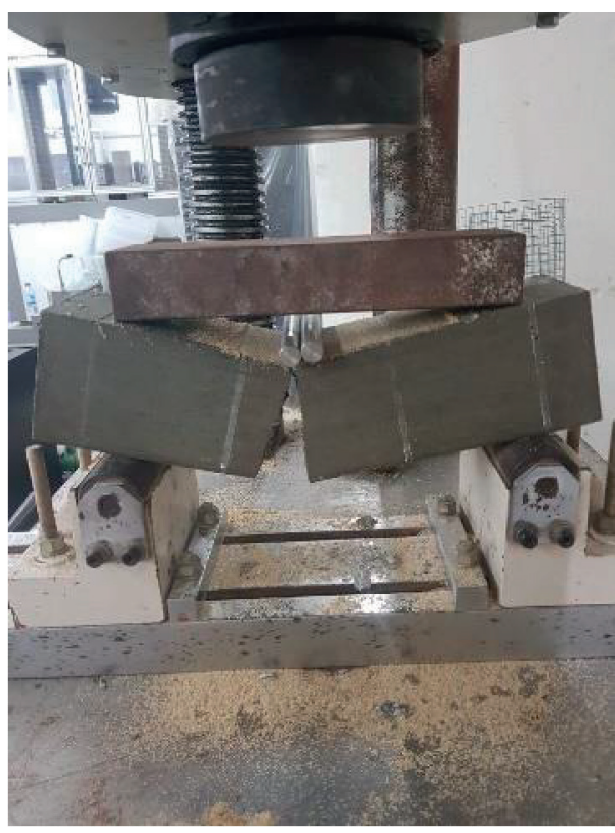

(b)

FIgURE 8: Measurement of (a) compressive and (b) flexural strength.

mock-up tests textures is collected as shown in Table 2. The parameters were measured after exposing aggregates within 24 to 26 hours. In the laboratory, thirty-six EAN Laboratory were collected from the concrete samples. Additionally, $\mathrm{EAN}_{\text {Mock-up }}$ was extracted from forty-five locations in the field test.

Constructability of exposed aggregate concrete overlay is investigated through the comparison of the measured EAN from the laboratory and from the mock-up test with the designed EAN as described in Figure 9. Normality tests of both data are initially applied to investigate the data distribution as shown in Figure 9(a). Collected EAN $\mathrm{L}_{\text {Laboratory }}$ and $\mathrm{EAN}_{\text {Mock-up }}$ provided a $p$ value of 0.167 and 0.125 , respectively, and they were higher than the significant level of 0.05 . Thus, the data were significantly normal distribution, and the mean value of $E A N_{\text {Laboratory }}$ and EAN $\mathrm{N}_{\text {Mock-up }}$ was 44 . A statistical comparison was also conducted by $t$-test approach. The statistical test indicated that $\mathrm{EAN}_{\text {Laboratory }}$ and $\mathrm{EAN}_{\text {Mock-up }}$ were statistically equal. This confirmed that construction technique, environment, and curing method have no influences on EAN. Also, this verified that the targeted EAN in the field can be achieved by mobile mixer and mobile steel brush, and $\mathrm{EAN}_{\text {Laboratory }}$ can sufficiently show the constructability of EACO in the real field construction.

6.2. Mean Texture Depth (MTD). Mean texture depth (MTD) is measured and collected from the laboratory and mock-up test as shown in Table 3 . The sand patch test was conducted to compute the MTD on the surface of exposed aggregate concrete. MTD was recorded based on the diameter of the sand patch. In the laboratory, six locations of diameter were measured on each sample. For mock-up tests, MTD was derived from twelve locations for each slab.
Mean texture depths (MTDs) measured from the laboratory and mock-up test are compared in Figure 10. Initially, the normality test was performed on both data. Data of $\mathrm{MTD}_{\text {Laboratory }}$ and $\mathrm{MTD}_{\text {Mock-up }}$ provided the significant level of 0.154 and 0.2 that was higher than 0.05 . This confirmed that both data were statistically normal distribution. Additionally, average $\mathrm{MTD}_{\text {Laboratory }}$ and $\mathrm{MTD}_{\text {Mock-up }}$ were 1.19 and $1.08 \mathrm{~mm}$, respectively. Through $t$-test comparison of both data, $\mathrm{MTD}_{\text {Laboratory }}$ was not statistically equal to

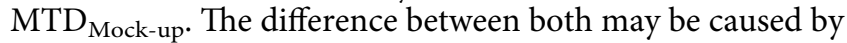
the environment condition, curing condition, and construction method. Also, $\mathrm{MTD}_{\text {Mock-up }}$ was slightly lower than that in the laboratory. Despite, both tests can produce MTD that met the surface texture criteria.

6.3. Compressive Strength. Early compressive strengths measured from mock-up and laboratory test are shown in Figure 11. All compressive strengths in mock-up and laboratory test satisfied the structural requirement for early traffic opening of concrete overlay. Mean compressive strengths were compared between the laboratory and mockup test samples by the $t$-test method. 3-day and 7-day compressive strengths of laboratory samples were statistically equal to those of the mock-up test. This indicated the ability of mobile mixer and deck finisher to produce exposed aggregate concrete overlay to meet the design criteria.

6.4. Flexural Strength. 3-day and 7-day flexural strengths of exposed aggregate concrete overlay that were constructed in mock-up and laboratory tests are recorded as illustrated in Figure 12. All flexural strengths derived from both tests were acceptable with the requirement of early traffic opening. 3-day strength of the laboratory test was slightly 
TABLE 2: Collected exposed aggregate number from laboratory and mock-up tests.

\begin{tabular}{|c|c|c|c|c|c|c|}
\hline \multirow[t]{2}{*}{ Sample } & \multicolumn{3}{|c|}{ EAN (laboratory) } & \multicolumn{3}{|c|}{ EAN (mock-up test) } \\
\hline & 39 & 42 & 42 & 41 & 42 & 41 \\
\hline \multirow[t]{3}{*}{1} & 40 & 45 & 37 & 39 & 45 & 44 \\
\hline & 41 & 40 & 41 & 40 & 36 & 46 \\
\hline & 41 & 47 & 46 & 40 & 47 & 39 \\
\hline \multirow[t]{3}{*}{2} & 44 & 49 & 44 & 41 & 45 & 37 \\
\hline & 44 & 40 & 37 & 49 & 37 & 44 \\
\hline & 46 & 45 & 47 & 47 & 41 & 45 \\
\hline \multirow[t]{3}{*}{3} & 47 & 50 & 46 & 47 & 50 & 46 \\
\hline & 48 & 48 & 45 & 44 & 46 & 48 \\
\hline & 43 & 43 & 41 & 43 & 60 & 48 \\
\hline \multirow[t]{3}{*}{4} & 46 & 46 & 48 & 50 & 57 & 51 \\
\hline & 38 & 40 & 40 & 45 & 39 & 38 \\
\hline & - & - & - & 37 & 50 & 44 \\
\hline \multirow[t]{2}{*}{5} & - & - & - & 46 & 37 & 42 \\
\hline & - & - & - & 48 & 41 & 46 \\
\hline
\end{tabular}
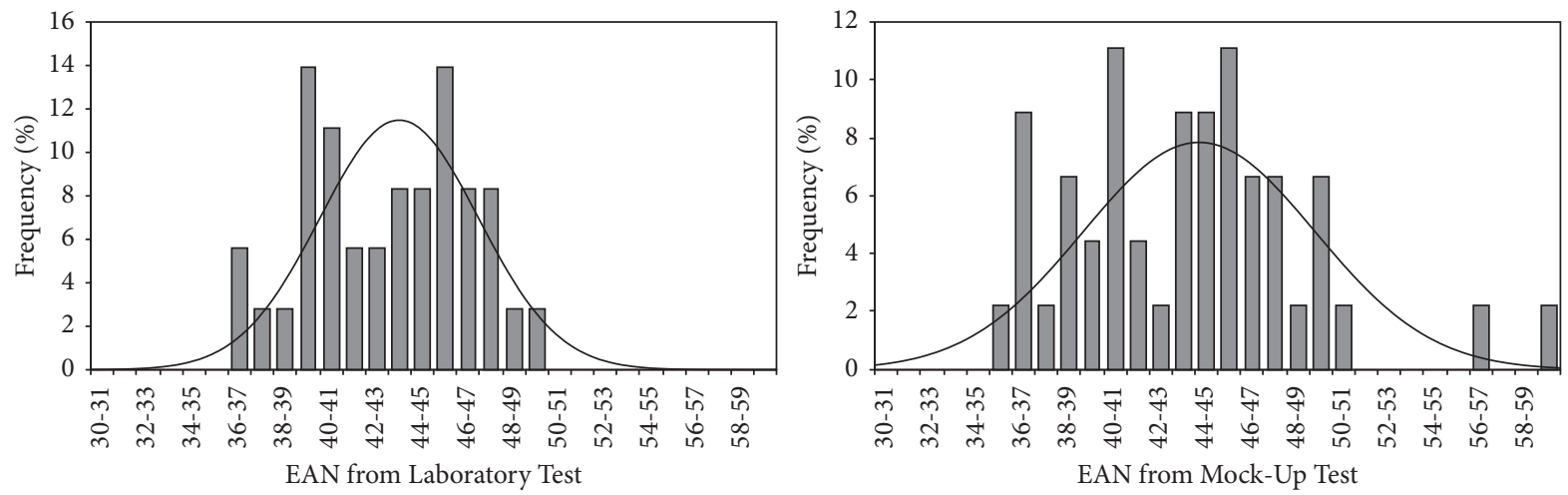

(a)

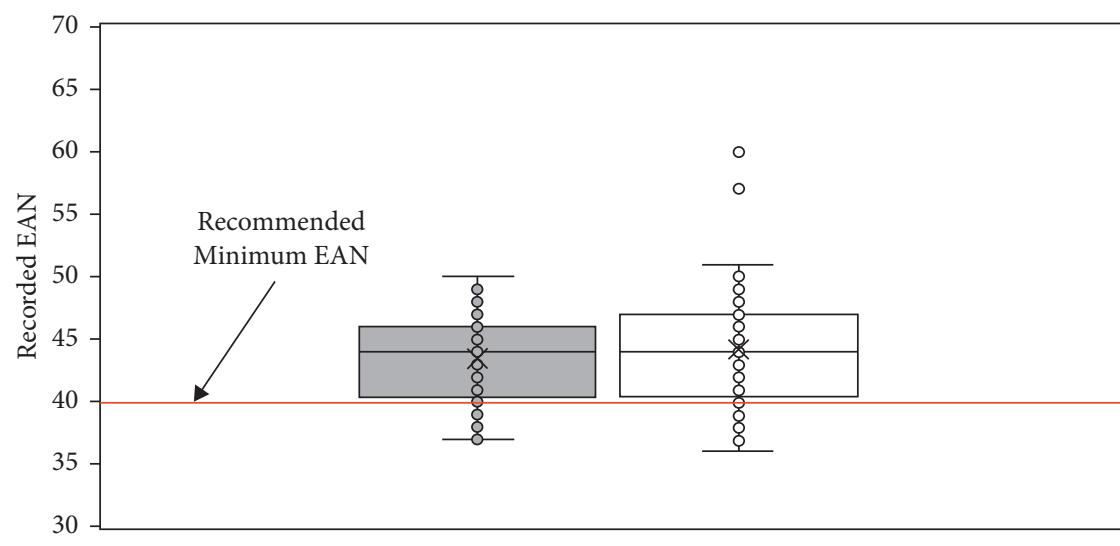

EAN Laboratory

EAN Mock-Up

(b)

FIGURE 9: Comparison of exposed aggregate number from laboratory and mock-up test: (a) comparsion of data distribution for EAN in the laboratory and mock-up test; (b) statistical comparison of exposed aggregate number. 
TABLE 3: Collected mean texture depth from the laboratory and mock-up test.

\begin{tabular}{|c|c|c|c|c|c|c|}
\hline \multirow{2}{*}{ Sample } & \multicolumn{2}{|c|}{ MTD (laboratory) } & \multicolumn{4}{|c|}{ MTD (mock-up) } \\
\hline & 1.48 & 1.41 & 1.10 & 1.10 & 1.10 & 1.17 \\
\hline \multirow[t]{2}{*}{1} & 1.37 & 1.44 & 1.10 & 1.10 & 1.10 & 1.10 \\
\hline & 1.41 & 1.52 & 1.24 & 1.10 & 1.10 & 0.98 \\
\hline \multirow{3}{*}{2} & 1.15 & 1.11 & 0.98 & 1.10 & 0.98 & 1.10 \\
\hline & 1.26 & 1.2 & 1.10 & 1.10 & 1.10 & 1.10 \\
\hline & 1.11 & 1.23 & 1.10 & 1.10 & 1.10 & 1.10 \\
\hline \multirow{3}{*}{3} & 0.96 & 1.07 & 0.98 & 0.98 & 0.98 & 1.10 \\
\hline & 1.05 & 1.16 & 0.88 & 0.98 & 0.98 & 0.98 \\
\hline & 1.18 & 1.24 & 1.10 & 1.10 & 1.10 & 1.10 \\
\hline \multirow{3}{*}{4} & 1.02 & 0.96 & 1.10 & 0.98 & 0.88 & 0.98 \\
\hline & 1.07 & 0.96 & 1.04 & 1.10 & 0.98 & 0.98 \\
\hline & 1.1 & 1.13 & 0.98 & 1.10 & 1.10 & 0.98 \\
\hline \multirow{3}{*}{5} & - & - & 1.24 & 1.42 & 1.24 & 1.24 \\
\hline & - & - & 1.24 & 1.10 & 1.24 & 0.98 \\
\hline & - & - & 1.24 & 1.17 & 1.17 & 1.04 \\
\hline
\end{tabular}
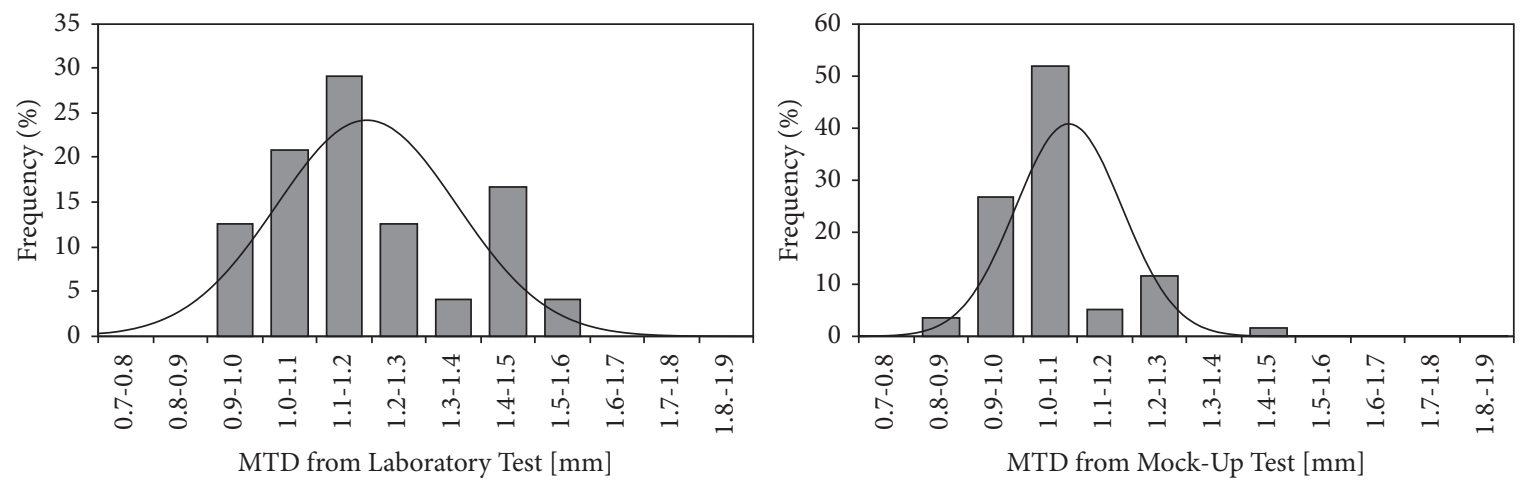

(a)

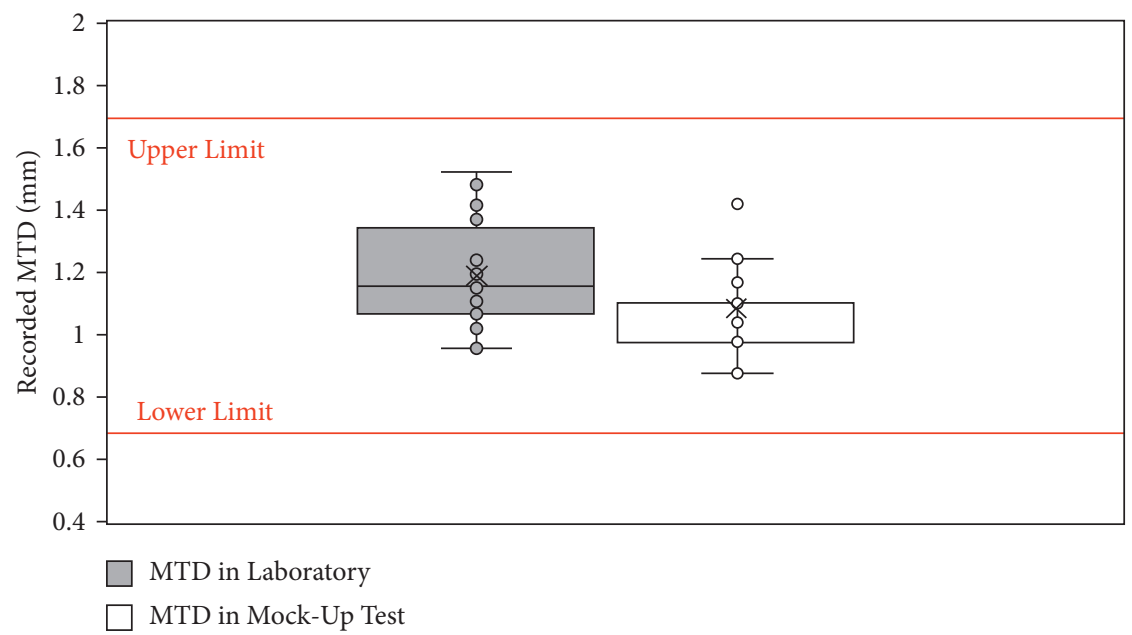

(b)

FiguRE 10: Comparison of mean texture depth from the laboratory and mock-up test: (a) collected mean texture depth from the laboratory and mock-up test; (b) statistical comparison of mean texture depth from the laboratory and mock-up test. 


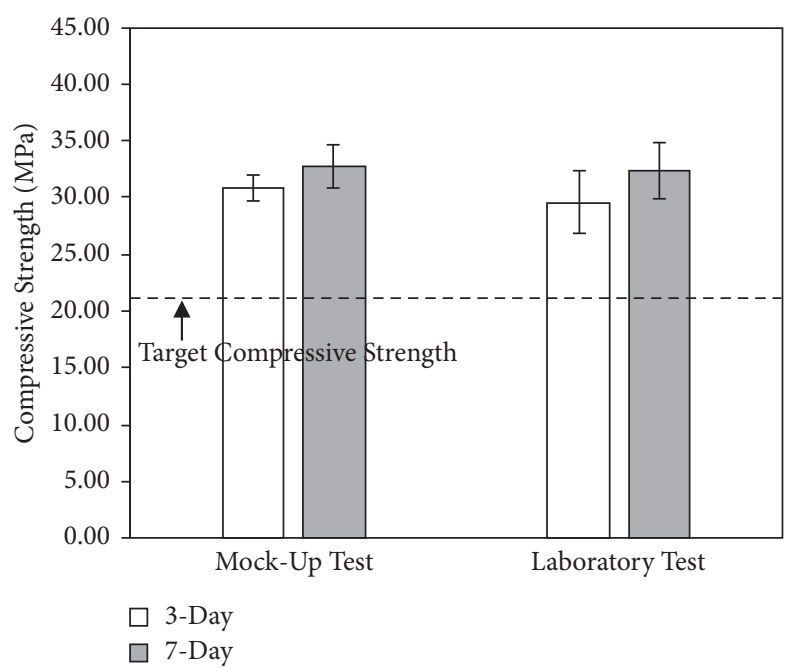

FIGURE 11: Comparison of compressive strength in mock-up and laboratory tests.

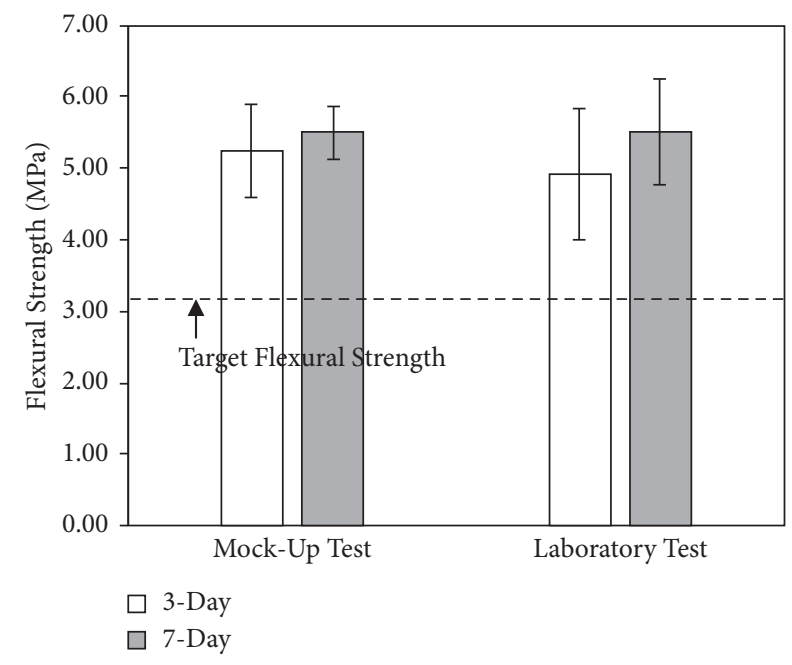

Figure 12: Comparison of flexural strength in mock-up and laboratory tests.

smaller than that of the mock-up test about $0.6 \mathrm{MPa}$. Moreover, both tests generated a slight difference of 7-day flexural strength. According to $t$-test statistical comparison, flexural strengths of laboratory and mock-up samples were equal. Therefore, strength target of exposed aggregate concrete overlay can be achieved by the utilization of mobile mixer and deck finisher. Also, laboratory strength can be an adequate indicator to verify this structural performance in the field.

\section{Recommended Construction Guideline of Exposed Aggregate Concrete Overlay}

In situ surface textures and structural performances of exposed aggregate concrete overlay were validated through mock-up test construction. EAN, MTD, and structural strengths of the mock-up test met the concrete overlay criteria. Thus, this study recommended the construction

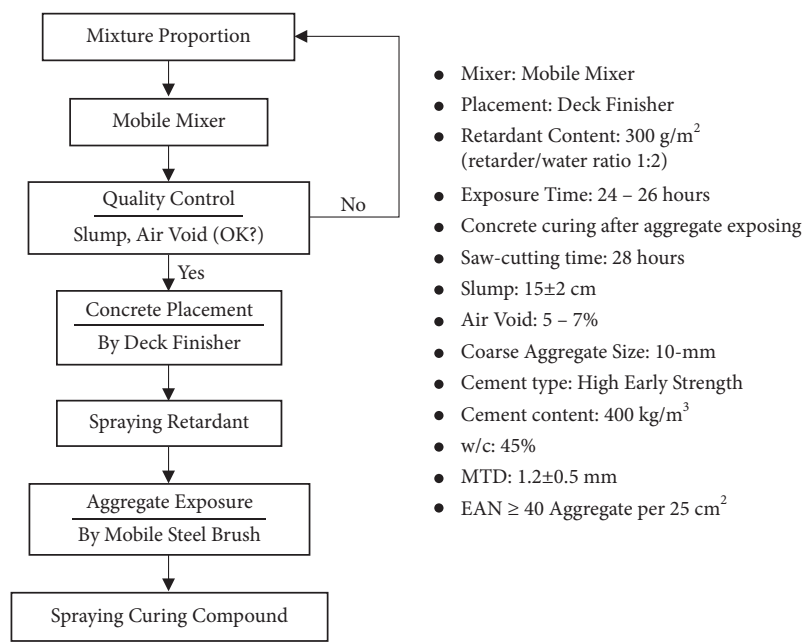

FIGURE 13: Recommended construction guideline and criteria.

guideline and criteria as shown in Figure 13. Quality of fresh concrete is controlled by slump and air void tests to secure the constructability. Slump and air void of concrete can be adjusted by adding the superplasticizer and air entraining admixtures during each mixing. After achieving the required slump and air void, concrete can be placed and finished by deck finisher. Subsequently, the retardant agent is sprayed on the fresh concrete surface to delay the setting process. Within 24 to 26 hours, mobile steel brush removes the unset surface mortar and exposes the aggregates to meet the surface texture criteria. Lastly, curing compound is applied on the exposed aggregate concrete slab. EAN and MTD must meet the recommended value to obtain the low-noise surface texture. Required strengths should be also achieved to secure the early traffic opening.

\section{Conclusions}

Exposed aggregate concrete pavements are typically provided by batch plants for the new pavement construction. However, for pavement rehabilitation purpose, concrete product is manufactured by different methodology. This study applied the mock-up tests to verify the constructability of low-noise exposed aggregate concrete overlay produced by mobile mixer and deck finisher. Surface texture parameters, such as exposed aggregate number (EAN) and mean texture depth (MTD), and concrete structural strength were also evaluated with the design criteria and compared with those measured from the laboratory test. With this investigation, a construction guideline of exposed aggregate concrete overlay was suggested and significant findings were as follows:

(i) Mobile mixer and deck finisher showed its effectiveness to produce a target exposed aggregate concrete material that ensures the required surface texture for low tire-pavement noise and structural strength at early age for overlay construction.

(ii) Exposed aggregate number (EAN) from the laboratory and from the mock-up test was statistically 
equal with the mean values of 44 which satisfied the EAN criterion for low tire-pavement noise in exposed aggregate concrete overlay. This confirmed that EAN was not significantly influenced by construction methods or environment conditions.

(iii) Average mean texture depth (MTD) from laboratory and mock-up test samples was 1.19 and $1.08 \mathrm{~mm}$, respectively. Even though MTD from both tests met the required value, both samples were statistically different. MTD from the mock-up test was smaller than that from the laboratory due to the environmental condition, curing condition, and exposure device.

(iv) Even though concrete production and construction procedure was different in the laboratory and mockup test, structural strengths from both situations were statistically equal and they also met the structural criteria for early traffic opening.

This research enabled an applicable methodology of field construction for exposed aggregate concrete overlay to maintain a surface texture for low tire-pavement noise and early structural strength. However, the effect of construction procedure on different concrete mixtures and on the long-term performances of concrete overlay shall be farther investigated in order to establish an adaptable and cost-effective methodology of pavement rehabilitation.

\section{Data Availability}

Some or all data, models, or code that support the findings of this study are available from the corresponding author upon reasonable request.

\section{Conflicts of Interest}

The authors declare that they have no conflicts of interest.
Transportation Research and Development, vol. 7, no. 2, pp. 22-27, 2013, English Edition.

[5] B. Descornet, F. Fuchs, and R. Buys, "Noise-reducing concrete pavements," in Proceedings of the In Fifth International Conference on Concrete Pavement Design and Rehabilitation, Purdue University, West Lafayette, Indiana, USA, April 1993.

[6] M. Monazewska, "Surface criteria for exposed aggregate concrete surface (low noise surface for roads)," in Proceedings of the Third international Symposium on Pavement Surface Characteristics, Christchurch, New Zealand, September 1996.

[7] H. Sommer, "Noise Reducing Concrete Surface - State of the Art 1992," Noise Reducing concrete Surfaces, pp. 8-34, PIARC Workshop, Vienna, 1992.

[8] R. L. Wayson, NCHRP Synthesis 268 - Relationship between Pavement Surface Texture and Highway Traffic Noise, Transportation Research Board, National Academy Press, Washington D.C, USA, 1998.

[9] H. Sommer, "Developments of the exposed aggregate technique in Austria session 8 - noise reducing surfaces," in Proceedings of the Seventh International Symposium on Concrete Roads, pp. 133-136, Viena, October 1994.

[10] C. Caestecker, "Test sections OF noiseless cement concrete pavements," in Proceedings of the International Purdue Conference on Concrete Pavement Design and Materials for High Performance, Indianapolis, Indiana, USA, August 1997.

[11] S.-W. Lee, Y.-K. Kim, D.-H. Choi, J.-W. Shim, and T.-S. Yoo, "A suggestion of mix, construction method and quality control criteria of fine-size exposed aggregate PCC pavement by experimental construction," Journal of the Korean Society of Road Engineers, vol. 13, no. 3, pp. 51-63, 2011.

[12] J. H. Kim, Y. K. Kim, and S. W. Lee, "Noise characteristics of fine-size exposed aggregate concrete pavement in Korea and abroad," International Journal of Highway Engineering, vol. 20, no. 6, pp. 11-20, 2018.

[13] KCS, Bonded Concrete Overlay, Korean Construction Standard, KCS449910 Ed. edition, 2018.

[14] ASTM, Standard Test Method for Measuring Pavement Macrotexture Depth Using a Volumetric Technique, ASTM International, vol. E965-15, West Conshohocken, PA, USA, 2015.

\section{Acknowledgments}

This research was supported by Basic Science Research Program through the National Research Foundation of Korea (NRF) funded by the Ministry of Education (2021R1A6A1A03044326).

\section{References}

[1] Acpa, Guide To Concrete Overlays: Sustainable Solutions For Resurfacing And Rehabilitating Existing Pavements, ACPA Publi, American Concrete Pavement Association, Skokie, Ill, 2008.

[2] J. R. Jaeckel, D. A. Kuemmel, Y. Z. Becker, A. Satanovsky, and R. C. Sonntag, "Noise issues of concrete-pavement texturing," Transportation Research Record: Journal of the Transportation Research Board, vol. 1702, no. 1, pp. 69-79, 2000.

[3] N. C. Kim, A Study on the Surface Texture Characteristics of the Exposed Aggregate PCC Pavements, Gangneung-Wonju National University, Gangneung, South Korea, 2005.

[4] Y. Liu, B. Tian, and K.-m. Niu, "Research on skid resistance and noise reduction properties of cement concrete pavements with different surface textures," Journal of Highway and 